\title{
THE NECESSITY FOR COMPETENT GEOLOGICAL SURVEYS OF GOLD MINES.
}

\author{
By NICOL BROWN F.G.S \\ (Read June 7 th, 1895.)
}

\section{INTRODUCTION.}

$\mathrm{T}^{\mathrm{H}}$ $\mathrm{HE}$ late Mr. Jevons wrote a paper in $\mathrm{I} 859$, entitled "Remarks on the Australian Gold Fields," to which far-seeing memoir the writer's attention was drawn by a kindly critic in The Manchester Guardian, after he had written and delivered a lecture in Glasgow on "The Profit and Loss of Gold-mining."

Mr. Jevons foreshadows the time "when greater experience is attained in quartz-mining, now so new an employment; when improved machinery is brought into use for the rapid, complete, and cheap extraction of the gold from the quartz matrix; when capital is attracted in great sums to the pursuit; and when the search for new auriferous reefs, becoming more keen, is rewarded," as he says he believes it will be, "by abundant discoveries." He finally draws two conclusions :

I. "That no great and recurring discoveries of alluvial gold are to be expected, so that the yield of alluvial gold must notably yet gradually fall off."

II. "That the supply of gold from its quartz matrix is subject to entirely different laws; that we at present know no limit to the amount procurable with the aid of capital; and that that amount, whatever it may be, will probably remain constant for a long period of time."

At the present time the supply of gold can be drawn, not only from the quartz reefs referred to by Mr. Jevons, but from sedimentary rocks; those from which the largest supplies are at present drawn being the Witwatersrand Conglomerates.

It has, however, laken many years to realise Mr. Jevons' forecasts, as the Gold industry appears to have been one of the slowest to adopt true scientific methods of working, the neglect of which is so detrimental to any practical undertaking.

We shall try to show that Geology in competent hands is the first necessary science for gold-mining ; and that no sure foundation is laid for other men of science to base their work on, unless the preliminary work of the geologist is well done. Geologists hold

FEbruary, 1896.] 
the key of the earth's storehouses of the royal metal ; but until lately, owing to few or no scientific methods being used, they, like other careful men, eschewed having anything to say about gold mines.

We hope to be able to show that Geology may do a useful work in clearing away those strange and baseless (and may be oriental) superstitions about subterranean storehouses of gold, which have followed it through all time and led to extravagance and failure in many ways.

Here is a little fossil, the rare helmet-shaped Cassidaria, rolled out of the Red Crag on the banks of the River Deben. To find it would have given many a geologist a delight comparable with that of finding a nugget rolled out of the golden sands of Africa. The possession, however, of golden dust from Africa is of great practical importance to us and all the human race, but until the finding of it receives the consideration of competent geologists, the industry will not attain the stability which is so much required, and which $\mathrm{Mr}$. Jevons, as a political economist, predicted so truthfully it would eventually acquire.

Some practical men would tell us they would rather have the gold than our Cassidaria; but, curiously, when these so-called "practical" people seek for the gold in the earth they cannot find it, or find it only by haphazard.

Whether a man goes to seek fossil shells or golden sands, the same qualities are required for success ; the same intimate knowledge of Nature and Nature's laws, without which her thrilling secrets cannot be discovered. From the want of this knowledge, the ordinary, uninstructed gold-seeker always defeats the end he has in view. He works hastily and by imperfect methods, and never stops to mark the finger-posts or compass-points which might guide him to the object of his search.

The gold in itself is too much over-estimated; a great portion of mankind, on merely looking at gold, are prepared to bow down and worship it as a kind of fetish, yet it is almost practically useless except for jewels and ornaments; it has to be alloyed with stronger metals before it can be used even as rings or coins. Pure gold is absolutely useless except for standardising purposes. Taken weight for weight, one ton of iron is infinitely more valuable in the workshop than one ton of gold. In the arts, silver, copper, iron, and even the alloy, pewter, can be used to more advantage by the skilled artist than pure gold. As the taste for true art increases, so may we look for the decrease in gold used for ornamental purposes.

In commerce the case is quite different. When one country (call it A) has exported more value in kind to another country (call it $B$ ) than $A$ has imported from $B$, then $B$ must pay $A$ the difference in gold, which has a fixed value. This is called the balance of exchange, and it is for this purpose that it is 
principally required. Gold has been described as "the wind of commerce and the tide of trade." It does not create commerce, but keeps it in motion.

The disturbance of the currency which has so long hung as an uncertain factor over the commercial world, appears to have arisen from a want of a sufficient supply of gold. The commercial world wants more gold, so as to meet the expanse of trade and prevent unnatural depressions.

The finding of nuggets by chance, has always set the lazy and the speculative upon the qui vive, and it was thus that much of the occupation of gold-seeking was left, until lately, in the hands of non-industrial people. Even now, there are but few bankers in England who would dare to come forward and justify the investing of money in gold-mining; and yet the banker's business is dependent upon a liberal supply of gold.

The finding of gold must no longer be left to chance, but should be the result of well-designed and well-organised efforts; and the basis of that industry which is now being built up, we must reiterate, rests on Geological Surveys made by qualified men. These are now demanded and must be obtained, and the gold-miners can well afford to pay for them, and at a different rate to what hitherto has been done.

Who would think of buying a ship nowadays without a Certificate of Survey by Lloyd's qualified surveyors, and who would think of acceptlng a certificate of survey from such a man as a quartermaster or a stevedore; and yet mines are daily sold in the City of London on the certificates of men who hold positions in the mines such as that held by a quartermaster or stevedore of a ship, and responsible directors of companies even raise such men to the position of captains or managers of mines.

Looking back to the olden times, we find that gold locked in refractory rock-material, such as pyrites, was practically unattainable by the ancients; and the Mosaic expression, "And' the gold of that land was good," no doubt meant that the gold of the river-sand was free, attainable gold.

Wherever mining in rocks was carried on by the ancients, it was not pursued to a great depth, and ceased so soon as they came to pyritous ore. The ancients seem to have had some idea about the way in which gold and silver are distributed in nature, in fact clearer ideas than shown by many modern people. In the Book of Job, as Murchison* points out, the natural truth is clearly expressed :

"Surely there is a vein for the silver ... the earth hath dust of gold."

And he drew attention to the fact that silver-lead veins were

* Siluria, 3rd Edn., 1867 , page 475. 
known to expand downwards in the earth, with great possibilities of future production, whereas gold, though extensively, is more thinly distributed.

The diagram, Fig. I, shows the relative production of gold and silver for the last fifty years. Taking the lower curve trom the date of Jevons' paper, 1859 , referred to above, it will be observed that the gold product fell off slightly till quite lately, owing to the failure of supplies from alluvial deposits ; and it is now increasing owing to permanent supplies from rock-crushing, as he predicted.

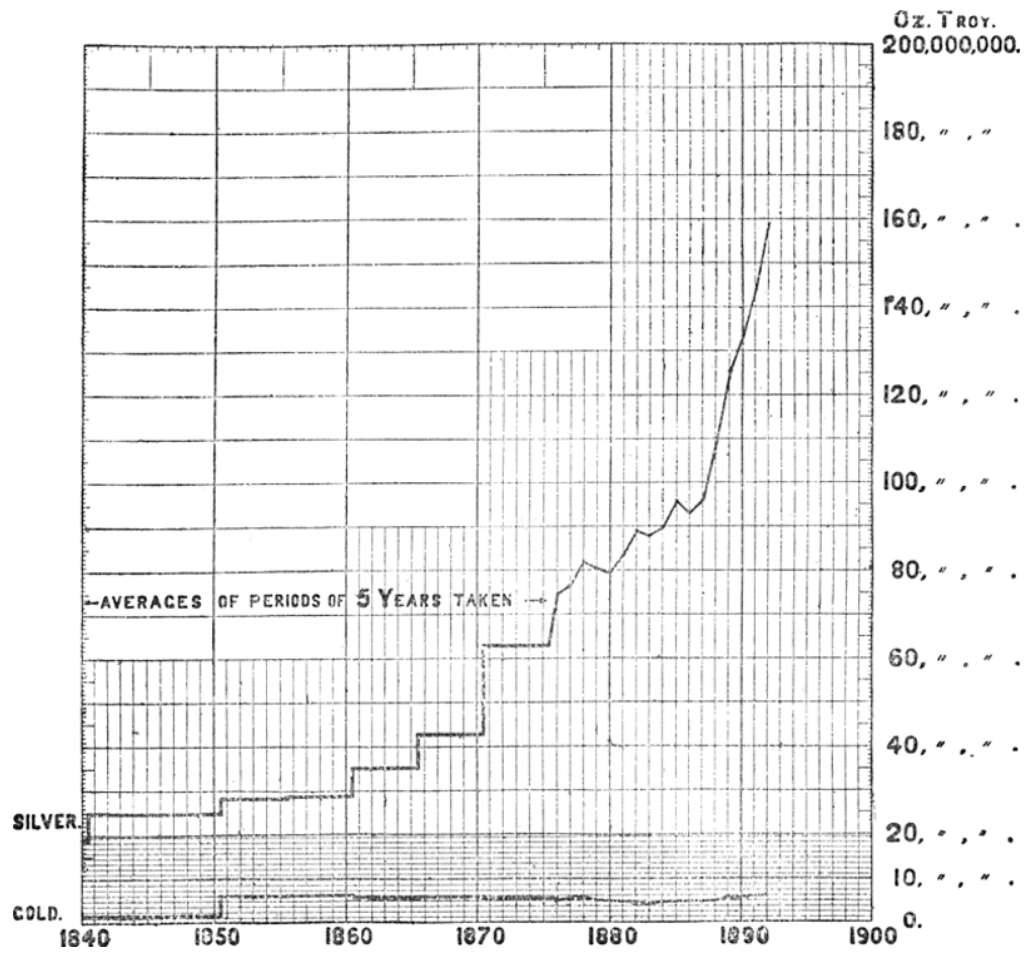

Fig. I.-TAble of THE Production of Gold aNd Silver for the IAST FIFTY YEARS,

From The Mineral Industry, Vol. II. (1893-94).

If the lower curve were divided, showing the gold from alluvial washing and quartz-crushing separately, the alluvial curve would be a decreasing one, and the quartz-crushing a rapidly-ascending one.

The production of silver increased, not only as foreshadowed by Murchison, but also owing to the abnormal stimulus of 
production given to it in America by the silver protection laws of that country.

Some of Murchison's views about gold were wrong, for instance, he limited the gold-bearing rocks to the older rocksystems, but he is apparently right on the point before us.

Gold-mining seems to have ceased entirely during the middle ages, as all surface gold in Europe had been previously picked up.

The necessity for gold in the mediæval times appears to have had at least two good effects. It inspired voyagers to seek for new lands, which were supposed to produce gold ; and a reference to their old maps and charts shows they are marked in different places with such notes as "Here is Gold." It also inspired the searchings of the Alchemists, which eventually led to the evolution of the Science of Modern Chemistry.

The voyages of Columbus and his successors were prompted by the hope of getting gold ; and the discovery of South America was so far successful that the hoards of the Incas were stolen and sent to Spain; but after these hoards were acquired the supply fell off, as only few fresh natural supplies were discovered. The quantity of gold the aborigines had, suggested to the invaders that there were great natural storehouses of it somewhere, and that in time these would be found.

It was thought gold and silver veins might yet be found as large and as rich as those of the inferior metals. Even such a wise man as Sir Walter Raleigh fell into the common snare when he dreamt of his El Dorado.

These absurd ideas, however, existed long before the Spanish Conquest of America.

Geology has now taught us the error of these delusive archaic dreams; and the cold material laws of Nature, as revealed by this science, tell us what may, and what may not, be found.

\section{Geological Surveys.}

We shall now endeavour to describe the part a geologist takes, together with others, in contributing to successful goldmining.

Directors of gold-mining companies have considerable diffcurties to encounter in selecting employés who understand the various departments of the work. To the uninitiated, these latter appear complicated; but in reality they are simple to those who take the trouble to spend the time and labour to learn about them.

Directors of gold-mining companies, should, however, themselves learn how to appoint their staff, and to control them by allocating to them their work in such a way as to get the best results. 
Instead of this, their aim has been to get what they call an "all-round" man, and thus try to shift the responsibility off their shoulders.

Owing to the confusion existing in the minds of such unskilled persons as to the proper administration of gold mines, the work of the different departments has often become hopelessly mixed. By these persons, the manager is expected to be a geologist, a miner, a mechanic, a chemist, and a businessadministrator all rolled into one; but evidently this leads to failure.

Pseudo-geologists, or prospectors without adequate knowledge, have been often employed to survey and report on the properties. Incapable persons also have been entrusted to do the industrial part of the work of mining, milling, and saving the gold.

All this blundering results in heavy loss. So largely has this been the case from the earliest times, that those who have taken the trouble to inquire into the facts, taking good and bad mines alike, have often made the statement that gold costs more to produce than it is worth.

Proper geological surveys, not only of the gold-bearing veins or beds, but of the enclosing rocks, must now take the place of the old prospector's empirical work, in order to prepare the field for the tools of the workers of the mine, who cannot otherwise proceed intelligently with their operations.

The costs of preliminary and concurrent surveys by competent geologists should always be provided for in any goldmining scheme. The expense of such surveys will be infinitesimal, compared with the money thrown away in times past on many expensive, abortive, El-Dorado-like schemes. Geological knowledge will tell them that there are no regular deposits of nuggets, but only the " mineralised" or metal-bearing beds of rock, which must be worked industrially before they yield up their treasures. When the "alluvial" fields of California and Australia were first discovered, it was only the nuggety gold which was sought for amongst the river-sands, and the value of the hard rocks was little thought of.

If we refer to the annals of these gold-fields, it will be found what a terribly wild speculation this gold finding proved to be. Stories of the wonderful finds of those days linger in the memory of people still living. Wild, lawless, uncontrolled men flocked to those countries from every part of the world to make their fortunes in a day; and in extravagance and debauchery the majority spent it as fast as they had gained it.

It was slow work, after the subsidence of that gold fever, after the surface nuggets were picked up, for a legitimate gold industry to establish itself; yet such an industry did early spring up in California and Australia. Its development, however, was slow. It early took the form of hydraulic mining, which may be defined 
as the art of "extracting gold from gold-bearing detritus, i.e., surface deposits, placers, or washings, by means of [water under] great pressure discharged through pipes against the auriferous material . . . the value of this kind of mining is based on the great facility with which profitable results can be obtained at trifling cost from washing vast areas of ground which contain relatively per cubic yard insignificant amounts of precious metals, but in the aggregate, when expeditiously worked, give large renitinerative returns." ${ }^{*}$

The Geological ages of these deposits are Post-Tertiary and Tertiary.

The early result of the mining and milling of gold-carrying quartz-rock was not encouraging, from lack of special knowledge.

It is only a proper understanding of the way in which gold is locked up within the gravel, or in the sand and clay, the product of the stamps, that leads to a comprehension of the true method of obtaining gold cheaply, at a rate which will ofter profit to capitalists. Briefly, it is the proper handling of these hard or intractable substances which renders it possible for anyone to win the gold from their embraces. It is, therefore, necessary to understand in some degree the distribution of gold as seen in natuse. Nature must be properly studied before she reveals where her treasures are found. She delights to hide them so that the human race may exert their best talents in finding them.

Gold is found in very small quantities disseminated through the mass of granitic mountains; but so small that to grind up such mountains for their gold would be a costly and unremunerative operation. It is locally distributed in many alluvial deposits, and it is also found in sea-water, in the proportion of about one grain to the ton.

We often hear of rich patches of gold-ore being found in some mines. These should receive careful investigation, as the reports sometimes give rise to much mischief and trouble. Such patches may represent the natural concentration of gold into some place usually called a "pocket"; or it may be a segregation, such as an "eye." It may be very rich, but not extending far in any direction. Thus, if we take a nearly vertical vein (see Fig. 2 ), and suppose that the part A B has been denuded, and the greatest portion carried into the alluvial sands and gravels, it is possible that, owing to the percolation of surface waters carrying some natural solvent, a small portion of the gold may have been taken into the remaining portion of the lode so far down as $\mathrm{C}$, there locally enriching it. It is such partial enrichments, which, when met with by uninstructed men, are magnified into representative samples of the whole lode.

* "Hydraulic Mining in California," by A. J. Bowie, Junr., Trans. A merican Institute of Mining Engineers, Vol. vi 1877,1878 . 
Mining.

The mining operations should be under the control of an educated and experienced mining superintendent. He must be a practical working miner, and should have had experience in mining various ores in different parts of the world. It is a great disadvantage to employ a miner whose prejudices have been developed by long experience of one particular series of rocks, or of the physical structure of one country. Such

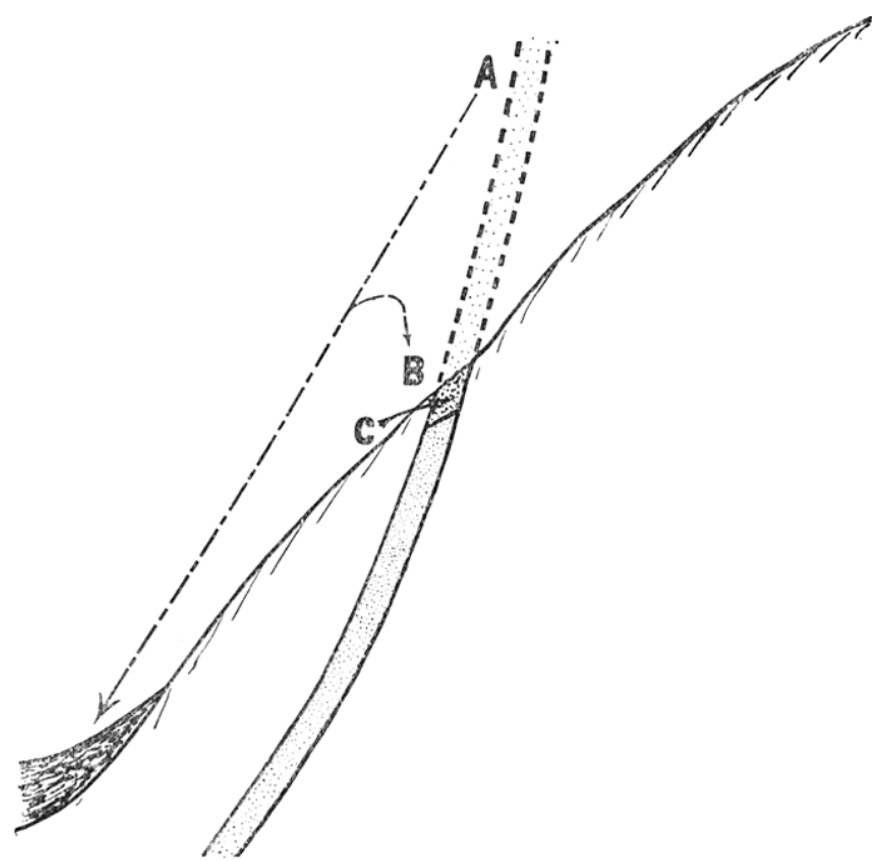

Fig. 2,-Diagram to Illustrate how a Vein may have been LOCALLY ENRICHED.

a man, however capable otherwise, has no resources when he comes to deal with new geological conditions. Unfortunately, many good mines have been condemned by such men.

The operations often reveal sections of the earth's crust which, when noted by the thoughtful geologist, lead to further following up of the payable deposits ; if, however, these sections are left unnoticed and unrecorded, rich opportunities are thrown away. 


\section{Mechanical-Crushing the Ore.}

Having "torn up the mountains by the roots," as mining was described in the book of Job, and brought the ore "to grass," the next operation is to mechanically crush it, in order to free the gold from the gangue; there is no evidence of this operation having been attempted by the ancients.

The stone-breakers, mechanical hammers, and various crushing appliances of all kinds, do on an artificial scale what earthmovements, the sea, ice, frost, and rivers, have always done with the rocks on a natural scale.

The Californian stamp-mill for crushing the ore is an improvement in detail and adaptability on the old Cornish mill used in tin-stamping, which has been in vogue since the seventeenth century.

By these stamp-mills, which are at present the chief means of crushing, the ore is reduced to a fine state of subdivision, and the battery is flushed with water to act as a carrier of the finelydivided ore or pulp from under the hammers. This pulp is carried over plates coated with mercury, which catches a certain amount of gold, and so saves it in the form of an amalgam of gold and mercury.

The general result of this treatment is great loss in float gold and loss of gold in slimes.

A newer method, which is now attracting much attention, but may not be applicable to all kinds of ores, is to crush the ore dry. This makes the product easier to deal with when a percolation chemical process is used for dissolving the gold out of the ore instead of taking it out by amalgamation with mercury.

At the Witwatersrand the power is obtained from steam ; and, as there is a coalfield in the neighbourhood, this is easily and cheaply obtained. Johannesburg owes its rapid rise to being on a coalfield as well as on a goldfield; the combination of the two has caused the success of the place.

We can also obtain power from water, and, with the aid of electricity, transmit the power even for a hundred miles, and, if need be, drive machinery in a mine which may be on the top of a hill. With water power near them, mines have as good a factor for work as if they were near a coalfield. This greatly widens the areas in which gold ores can be worked, and operations formerly impracticable can now be carried on at a profit.

\section{Metallurgical and Chemical Processes.}

Although, as observed above, the origin of modern chemistry sprang from the searchings of the alchemists, whose aim was principally to make gold out of some other metal, it is strange that, while the ancient chemist devoted so much attention to 
gold, the modern chemist has, until recently, left it severely alone. Even though scientific chemists have now become alive to the importance of their science in its application to gold-extraction processes, the commercial and so called practical men in charge of mines often do not see its full importance.

However, the "chlorination" process was introduced, and afterwards the "cyanide" process (the most recent of all the chemical processes now in practical use), and considering the short time the latter has been in vogue, it has had an extraordinary influence on the gold industry in South Africa and other places. The process is a simple one.

It was long known that the cyanides had an affinity for metallic gold; but, as they had also an affinity for the baser metals, the extraction of gold from ores by this means was not considered feasible. Mr. MacArthur and Dr, Forrest, however, discovered the interesting fact that "cyanide" in certain conditions had a strong selective affinity for gold, and that, by utilising this and employing weak solutions, the economical recovery of gold from ores might be accomplished.

Referring to the stamp battery treatment, it is found that the flocculent clayey tailings consolidate into hard and impervious masses which defy percolation; but if the sand grains had not been separated from the clay, they would have kept open channels for the percolation of the cyanide liquors. It is apparent, therefore, that the process of separating the sand and clay into two varieties of tailings is a mistake, if a percolation process is to follow.

A method of dry-crushing the ore, as indicated above, seems to be the best adapted for this process; and when this shall have been carried out practically, and the dry-crushed ore treated directly with the cyanide, without the use of mercury-covered plates, it is hoped that another stage may be reached in the profitable saving of gold.

There are many other processes competing for the success which the cyanide process has achieved; as yet there are none equal to it. There is, however, no finality in these matters; and the great impetus given to research will doubtless lead to good results.

\section{Examples of Good Geological Surveys.}

As an example of the kind of geological work which should precede any attempt at mining, let the reader procure the special geological reports on particular gold-fields-such as Professor William Nicholas' papers, The Golden Quartz Reefs of Australia and The Bendigo Quartz Reefs Strata, Mr. E. J. Dunn's Report on the Bendigo Gold-Fields of Australia, or Mr. A. R. Sawyer's Report on the Mashonaland Gold-Fields, or Professor Clayton's Report on the Montana Mine-and it will be seen how variously Nature has worked in each case, how carefully and cunningly she has hidden 
away her golden treasures in the folds of her garment, and how these treasures can only be found out by a painstaking study of the geology or physical structure of the earth. Such reports, had they existed only a few years ago, "would have saved enormous waste of time, labour, and lives." They are evidence that a better state of things is growing up in the gold industries, while the handsome dividends paid by some of the great gold-mining companies show the profits which may be derived from a careful working of the business, based upon intelligent and scientific treatment.

Mr. Harry Page Woodward's Mining Handbook to the Colony of Western Australia is another great advance in the dissemination of valuable scientific knowledge; and it has this great merit, that it was published well in advance of the general rush to these gold-fields. It has been written by a very competent man, and is prepared expressly for prospectors and strangers to the Colony who are interested in mining. It will thus supply many a hardworking man with a scientific "vade mecum" which will surely help him to do his work with less toil and more certain purpose than ever could have been dreamt of in the days of former "gold rushes." Instead of the ignorant cackle of the mining canteen, where prospectors have usually picked up their scraps of information, they have here the well-digested hints of an able geologist; and it argues well for the future of Western Australia that the van of the prospectors has been led by Mr. Harry Page Woodward.

Amongst the recent literature on the subjects which have been considered in this paper, mention may be made of "Curtis on Gold-quartz Reduction," a paper read before the Institution of Civil Engineers in 1892 ; Louis on Gold-Milling (1893), in which the costs of numerous mines throughout the world are detailed in tabular form; Abraham's New Era in the Witwatersrand GoldFields (1894), in which the average product of the ore of the district is given as 14 dwts. ; this, however, is only the product, and not the contents of the ore. It is better in practice to deal with the gold contents of the ore, and not the gold extracted from the ore, as, unless this is done, the probable losses always going on in the process are never discovered.

Mr. Abraham's book is, however, very valuable to all nterested in the Witwatersrand mines, as it gives the dip of the reefs and methods for approximately calculating the life of a mine in that district.

Mr. Hamilton Smith, jun., published in The Times in January, I 893, a report on the Witwatersrand Gold-Fields. That report led to the Prussian Government sending out a mining commissioner, Herr Bergrath Schmeisser, who came to similar conclusions as those of Mr. Hamilton Smith as to the great extent of the Witwatersrand deposits. 


\section{Cost of the Production of Gold.}

While yet the old style of gold-seeking prevailed and men were prepared to risk their all in hazardous adventures, unguided by sufficient geological knowledge, hoping to find a great subterranean store-house of gold, the cost was never counted or even thought of. They dreamt that the bare possibility of wealth which could be taken out of the earth by shovelfuls rendered the necessity of counting the cost needless.

The new style is quite different, and the most practical way of now counting the cost is by the number of pennyweights of gold. For instance, it is now usual to say that an ore carrying ten pennyweights of gold to the ton will cost seven pennyweights in its extraction. The cost varies, of course, with the difficulties of mining and extraction.

As ten pennyweights of pure gold are worth $f_{2} 2$ s. 4 d. it follows that, as seven pennyweights are worth $\ell_{\mathrm{r}} 9 \mathrm{~s}$. $7 \mathrm{~d}$., which is the assessed cost per ton of extraction, a profit is left of $\mathbf{r} 2 \mathrm{~s} .9 \mathrm{~d}$. per ton of the ore handled.

These low costs are possible for mining, milling, and cyanidizing the ore.

\section{Conclusion.}

Nearly the whole of the iron and copper obtained in ancient times has perished by the corroding action of the atmosphere; here and there an old battle-axe or a Greek helmet may have resisted the destroying influence of time; but, taken as a whole, it may safely be said that the work anciently spent upon obtaining these metals has all disappeared.

If the condition of gold is compared with other metals, it is seen to be quite different. Gold is a durable metal, and the gold now in use is mingled with the product of very many past centuries. In much of it are represented the rich surface nuggets found in primæval times, probably obtained by forced or slave labour, by the Phonicians, the Romans, and the Carthaginians. Some part of the actual gold of Solomon's temple, of the crowns and jewels of emperors and kings, whether Roman, Saxon, or Spanish, or the ancient hoarded stores of India, may be still handled in the sovereigns passing over the counters of any of our banks.

The total gold produced in the world for the thirty-seven years ending 1892 is by the best authorities estimated to be 2 I $7,000,000$ ounces; and, if it is reckoned as the product of ore carrying on an average one ounce to the ton, it will represent the crushing from $217,000,000$ tons of ore.

The space occupied by one ton of ore is 15 cubic feet; and, to obtain the above number of ounces, 3,255,000,000 cubic feet of rock would require to be removed and ground up. To give some idea of the work which has been done (and 
COAT FELL.

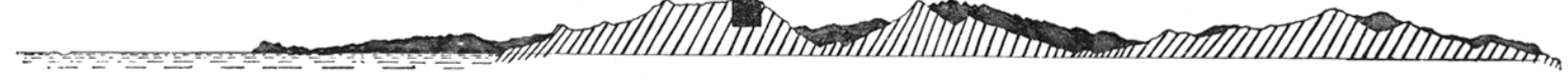

$\boldsymbol{E}$

SECTION VIEWED FROM NORTH.

w

$\stackrel{3}{8}$

rant

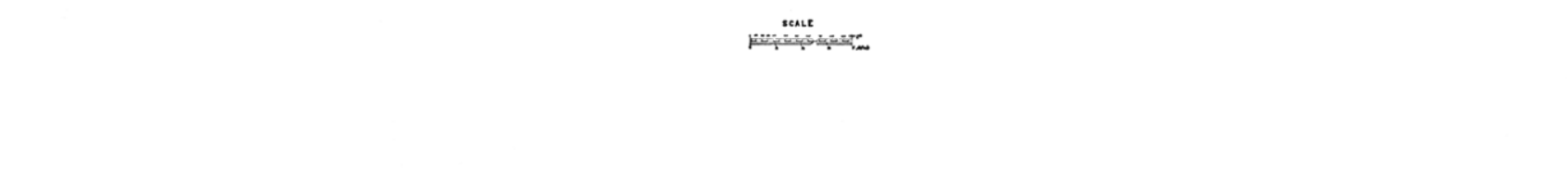

COAT FELL. 
which has really been very small) the small cube in the centre of Fig. 3 illustrates the amount of rock which would be removed out of such a hill as Goatfell, in Arran (which, of course, is nonauriferous) to obtain the results in gold during the said thirtyseven years. This is giving the calculation the credit of all gold obtained in hydraulizing as well as by quartz-crushing.

Or take another illustration, the number of tons of coal produced in the world during one year, is over $500,000,000$, or more than double the tons of quartz required to make the world's production of gold during the last thirty-seven years.

It has been the aim of this paper to show that the chance of men finding much gold in massive nuggets and becoming suddenly rich has for ever vanished. To continue the necessary supply of gold to carry on the ever-extending commerce of the world a vast industry of the first importance, aided by many sciences, is needed to gather out the infinitely small scattered portions of gold as they exist in nature.

The product in gold of the industry which has recently sprung up will afford relief to the straightened currency of the world; and, as it can now be procured with the industrial and scientific certainty predicted by Jevons, the result to the world will, in the near future, be very great.

The governor and directors of the Bank of England may hold the key of the bank's gold, but the geologists hold the golden key of knowledge to the earth's storehouses of the kingly metal ; and although it cannot be counted up like gold in the bank, they, and they only, can be relied on to survey the new gold-fields which may yet be found. If this be done, the still potent survivals of mediæval or oriental superstitions, ever ready to delude again and again a too gullible public, will definitely die out.

Men cannot nowadays keep slaves to work their gold mines as of old; but, always provided that they work upon the basis of proper geological surveys, the mining, mechanical, and electrical engineers, and the metallurgical chemists, with all the far-reaching fingers of their various sciences, can gather out the countless small particles of gold from the rock-matrices and pile them into the bank storehouses.

Industry must be set off against industry; our future gold, got by well-directed industry, will represent the result of men's honest toil.

Gold so obtained will reach a steady value, as compared with a speculative value; it will neither become greatly "appreciated" nor "depreciated," as the supply will constantly keep pace with the requirements of commerce ; it will help to keep the countless mills of many different industries in continuous motion, without intermittent periods of fluctuating trade, and thus bring benefits to many people in all parts of the earth.

FEBRUARY, I 896.] 